\title{
Filosofía para hacer las paces con niñas y niños. Un estímulo para la creatividad
}

\author{
Philosophy for making peace with children. An incentive for creativity
}

\author{
Sonia París-Albert / sparis@uji.es \\ orcid.org/0000-0003-1326-5078 \\ Universitat Jaume I, Castellón, España
}

\begin{abstract}
Banking pedagogy has always enjoyed a privileged position at schools. However, current societies demand alternative pedagogical models, which promote, on the one hand, greater participation of children, and on the other, dialogues to prompt reflection on topics alien to the contents of the classic school curriculum. According to a descriptive methodology that is based on critical analysis, Freire's liberation pedagogy is retaken in this text with the objective of proposing a philosophy for peace-making with children in order to stimulate their critical, ethical and creative thinking on questions related to peacebuilding and peaceful conflict transformation. So, Philosophy for making peace is understood as a liberation pedagogy that maintains most of the characteristics of the community of philosophical enquiry thought by Lipman and in which creativity has an essential role.
\end{abstract}

Key words: philosophy for making peace, liberation pedagogy, philosophy for children, community of philosophical enquiry and creativity.

Resumen: La pedagogía bancaria ha disfrutado de una posición privilegiada en las escuelas desde siempre. Sin embargo, las sociedades actuales demandan modelos pedagógicos alternativos que fomenten, por un lado, una mayor participación de las niñas y los niños y, por otro, diálogos para impulsar la reflexión sobre temas ajenos a los contenidos del currículum escolar clásico. Con una metodología descriptiva, basada en el análisis crítico, el texto rescata la pedagogía liberadora de Freire, a fin de proponer una filosofía para hacer las paces con niñas y niños, y con ello estimular su pensamiento crítico, ético y creativo sobre cuestiones relativas a la construcción de la paz y a la transformación pacífica de los conflictos. Así, entiende la filosofía para hacer las paces como pedagogía liberadora que conserva muchos de los rasgos de la comunidad de indagación filosófica de Lipman y en la cual la creatividad tiene un papel esencial.

Palabras clave: filosofía para hacer las paces, pedagogía liberadora, filosofía con niñas y niños, comunidad de indagación filosófica y creatividad. 


\section{Introducción $^{1}$}

Los análisis en torno a las pedagogías que predominan en las escuelas y a las maneras como podríamos transformarlas siguen estando muy presentes hoy en día. Este es el motivo por el cual este trabajo se adentra en una reflexión propia del ámbito de la filosofía de la educación, con la que se quiere proponer una filosofía para hacer las paces con niñas y niños en las escuelas, para favorecer su reflexión sobre cuestiones relativas a la paz y a la transformación pacífica de los conflictos desde edades tempranas, así como la construcción de una futura ciudadanía crítica, activa y comprometida, capaz de dar un mayor sentido propio al mundo.

Asumiendo que este es el objetivo principal de estas páginas, se recuperará la pedagogía bancaria y la pedagogía liberadora de Paulo Freire, mediante un recorrido por sus características definitorias, lo cual llevará a observar cuán presente sigue estando la primera en las escuelas y cuán pocos espacios se siguen concediendo a la práctica de la segunda.

De esta manera, los dos primeros apartados del artículo se referirán a los rasgos de ambos modelos pedagógicos, al tiempo que se irá exponiendo también la importancia de practicar una filosofía para hacer las paces con las niñas y los niños en las escuelas, la cual, entendida como práctica de la pedagogía liberadora y poniéndola en diálogo con la escuela de la Filosofía con Niñas y Niños, impulsará el pensamiento crítico, ético y creativo de las y los más pequeños.

En esta línea, la última sección del trabajo abordará de forma especial el papel del pensamiento creativo en relación con la propuesta de una filosofía para hacer las paces con niñas y niños como pedagogía liberadora, en la cual no podrán obviarse algunas de las investigaciones previamente realizadas en el ámbito de la peace research.

\section{Educación bancaria y saberes especializados. La narrativa del profesorado en las escuelas}

Cada vez son más las voces que se alzan en defensa de la práctica de pedagogías alternativas a las tradicionales en las escuelas, con las cuales potenciar

1 Este trabajo se enmarca en el proyecto de investigación “Testimonio ético y comunicación para el cambio: análisis de modos de re-significación de la figura de la víctima y de re-situación de los agentes sociales", con código P1·1B2015-21, financiado por la Universitat Jaume I de Castellón, España. 
continuamente el pensamiento crítico, ético y creativo de las niñas y los niños. Sin embargo y a pesar de la presencia de estas voces, las escuelas siguen nutriéndose mayoritariamente de propuestas pedagógicas que, basadas en la transmisión de saberes especializados, se centran en relatos narrados por el profesorado, los cuales otorgan a éste una primacía indudable frente a la pasividad del alumnado. Estos son los modelos educativos tradicionales que Freire relaciona directamente en sus estudios con lo que denomina pedagogía bancaria, en la cual "el educador hace comunicados y depósitos que los educandos, meras incidencias, reciben pacientemente, memorizan y repiten" (Freire, 1970: 76); de modo "que el único margen de acción que se ofrece a los educandos es el de recibir los depósitos, guardarlos y archivarlos" (Freire, 1970: 76).

A consecuencia de ello, "el educador aparece como un agente indiscutible, como su sujeto real, cuya tarea indeclinable es 'llenar' a los educandos con los contenidos de su narración" (Freire, 1970: 75), manteniéndose "en posiciones fijas, invariables” (Freire, 1970: 77) y mostrando explícitamente que es quién posee el saber a diferencia de las y los niños, quienes son siempre percibidos como las y los que no saben.

De esta manera, el profesorado, convertido en una autoridad, "lejano e intangible, rodeado de rumores vagos e impresionantes, está condenado al monólogo teatral" (Bourdieu y Passeron, 2001: 131), herramienta de la que se ayuda para depositar los contenidos en las niñas y los niños, sin ofrecer casi ningún tipo de posibilidad al diálogo, pues ciertamente con estos modos de proceder -al prestar más atención a la enseñanza y no al aprendizaje-, "el profesor puede solicitar la participación o la objeción de los estudiantes sin arriesgarse nunca a que éstas se instauren realmente" (Bourdieu y Passeron, 2001: 132).

De hecho, es tal su autoridad sobre la enseñanza, que las y los profesores se sienten incluso autorizados a "juzgar a los estudiantes en su esencia en tanto en cuanto que consideran su producción, exposición o disertación, como un ejército, un mero 'hacer' ficticio cuyo único fin es poner de manifiesto aptitudes virtuales y definitivas, es decir, esenciales" (Bourdieu y Passeron, 1967: 73).

En este sentido, no cabe duda de que influyen directamente en las niñas y los niños, al ser su carisma "una incitación permanente al consumo de cultura: la exhibición de virtuoso, el juego de las alusiones laudativas o de los silencios despectivos bastan para orientar, a veces decisivamente, la actividad del estudiante" (Bourdieu y Passeron, 1967: 70-71), suscitándole "la necesidad de los productos que dispensa” (Bourdieu y Passeron, 1967: 70). 
Tanto es así que, encarnando la norma y actuando "como espejo ante los ojos de los aprendices o de los alumnos respecto a la excelencia que, si todo va bien, lograrán en algunas semanas, meses o varios años más tarde" (Perrenoud, 1990: 39), al profesorado le basta con "mostrar cómo hacer algo, corrigiendo después los ensayos fallidos, para que, poco a poco, a través de ensayos y errores, se establezca y afirme el dominio" (Perrenoud, 1990: 41). En efecto:

El desdoblamiento de la imago profesional permite al estudiante identificarse con los valores que encarna el "buen profesor", pese a su repulsión por los profesores tiranos, machacones o aguafiestas. El profesor puede, incluso, ser garantía de la legitimidad de las posiciones que se adopten, por más alejadas que estén del universo escolar: ¿no realizan los estudiantes su "esencia singular", con la beatitud que normalmente acompaña a la perfección, cuando sirven a la misma causa política que sus maestros? (Bourdieu y Passeron, 1967: 69).

Con esta cita se da paso a otra de las características centrales de la pedagogía bancaria tradicional que hace alusión a la pasividad del estudiantado (Freire, 1970), la cual es fruto de las formas como se fabrica la noción de estudiante (Perrenoud, 1990), según la cual, generalmente, su oficio no es otro más que el de repetir y memorizar los mensajes del profesorado (Perrenoud, 2006), llegando a ser las y los mejores alumnos quienes mejor reproduzcan estos mensajes.

Esta idea es la que le sirve a Perrenoud (1990: 36) para hablar de las jerarquías de excelencia, que el autor define como aquella "jerarquía fundada en el grado en el que una práctica se aproxima a la excelencia, entendida como dominio efectivo, elevado grado de perfección”, y que aplicada al ámbito educativo, hace que el profesorado reconozca a las niñas y los niños como formalmente iguales (Bourdieu y Passeron, 1967: 47), como "alumnos iguales en derechos y en deberes” (Bourdieu y Passeron, 1967: 101), manteniendo unos criterios idénticos para todas ellas y ellos que, además de ser socialmente construidos, no prestan casi ningún tipo de atención a sus diferencias.

No hay duda de que "la igualdad formal que regula la práctica pedagógica sirve en efecto como máscara y justificación a la indiferencia respecto a las desigualdades reales ante la enseñanza y ante la cultura enseñada o, de manera más exacta, exigida" (Perrenoud, 2007: 28-29). Estas jerarquías son las mismas que hacen que,

cuando observa a sus alumnos en clase o cuando piensa en ellos, cuando corrige sus trabajos, redacta las anotaciones de su libreta o recibe a sus padres, cuando habla con un colega, el maestro juzga el nivel de excelencia de sus alumnos. Esta evaluación, que puede ser muy intuitiva, contribuye a confirmar o matizar la imagen que del alumno 
se hace el maestro. Esa imagen le conduce a menudo a formular una apreciación, un estímulo, crítica, consejo, a intervenir a veces de forma directa en el trabajo del alumno, mostrándole cómo hacerlo, pidiéndole que justifique una respuesta, cogiéndole el lápiz de las manos para ayudarle (Perrenoud, 1990: 227).

Esta visión pasiva fabricada del alumnado va de la mano también de la noción generalizada que se tiene de la niñez como una etapa de la vida (Kohan, 2011:341), en la cual las niñas y niños transitan durante un tiempo, hasta dejar atrás los rasgos propios de la infancia (Pavez Soto, 2012: 83-84), mientras se preparan para la edad adulta (Storme y Vliegue, 2011: 184).

Noción que encaja a la perfección con la definición que se da en la Convención sobre los derechos del niño (Naciones Unidas, 1989), donde se define a la niña o al niño como todo ser humano que tiene menos de dieciocho años, a no ser que en algún lugar concreto haya una ley específica que entienda la llegada a la edad adulta a una edad más temprana (Huynh et al., 2015: 10).

Desde este punto de vista, es fácil creer entonces "que las niñas y los niños están en tránsito para ser integrados plenamente en la sociedad, una vez que dejen atrás las características propias de la infancia y dejen de ser vistos como seres infantilizados" (Pávez Soto, 2012: 83-84). Se trata, por consiguiente, de una interpretación que alude constantemente al futuro y hace pensar en las niñas y los niños "como un 'proyecto de persona' o becoming, pero sin serlo totalmente en la vida presente” (Pávez Soto, 2012: 88), lo cual "ha tenido como consecuencia su exclusión de la vida social y pública" (Pávez Soto, 2012: 88).

En este sentido, las niñas y los niños son vistos como ese grupo de individuos "muy diferentes entre sí, pero que comparten una misma ubicación etaria en tanto 'menores de edad' sometidos a la autoridad adulta" (Pávez Soto, 2012: 92). Autoridad que en el modelo educativo tradicional, con la pedagogía bancaria, tal y como se señalaba en las líneas anteriores, es ejercida por el profesorado, con quien, gracias a la posición privilegiada de su narrativa, el sistema excluye prácticamente cualquier posibilidad de diálogo con el alumnado, negándose a un mismo tiempo la intervención y participación de las niñas y los niños en los asuntos que les afectan en el interior de las escuelas. Esto es, excluyendo la pluralidad de su voz.

Ciertamente, el relato narrado por el profesorado es la herramienta metodológica más usada en la pedagogía tradicional bancaria. Una herramienta que sin duda tiene un carácter unidireccional y unilateral, pues al dirigirse desde el profesorado al alumnado, tiene en cuenta sobre todo la perspectiva del primer agente en el proceso de enseñanza y aprendizaje, sin complementarla con la pluralidad de puntos de vista que las voces de los estudiantes pueden aportar. 
Se trata, por lo tanto, de una actividad, la narrativa, que conduce al saber más puramente teórico, así como a la "memorización mecánica del contenido narrado" (Freire, 1970: 76). Con este modo de actuar, es indudable que la pedagogía bancaria destacará "esencialmente, los saberes más académicos y racionales, las materias clásicas del curriculum, la super especialización, la división en compartimentos estancos del saber en materias o asignaturas, los métodos más discursivos o verbalistas..." (Dios-Diz, 2013: 159), reduciendo a su mínima expresión cualquier espacio para el diálogo y la reflexión sobre aspectos ajenos a los contenidos del currículum más clásico.

Estos son los motivos, por ejemplo, de la escasa presencia que hoy en día tiene en las escuelas la reflexión sobre la $\mathrm{paz}^{2}$ o sobre la transformación pacífica de los conflictos, ${ }^{3}$ concentrándose en días contados y dificultando de este modo no sólo la práctica de una posible filosofía para hacer las paces ${ }^{4}$ con

2 Cuando en este texto se habla de paz se toma como referencia la clasificación elaborada por Galtung (2003), en la que se distinguen tres cosmovisiones de paz en relación con tres tipos de violencia: 1) La paz negativa, que supone entender la paz en contraposición a la guerra, es decir, "la paz como ausencia de violencia". Esta paz va de la mano de la violencia directa, aquella que tiene lugar en un momento determinado y provoca un daño inmediato sobre la víctima. 2) La paz positiva, que supone entender la paz por sí misma, como una situación en la cual las necesidades humanas básicas están cubiertas, favoreciendo así las situaciones de justicia. Esta paz va de la mano de la violencia estructural, aquella violencia menos visible, que se prolonga en el tiempo y cuyos daños se observan a más largo plazo, no de una forma inmediata. 3) La cultura de la paz es la cultura que potencia valores de paz positiva y que se relaciona con la violencia cultural, la cual se distingue a través de símbolos, gestos..., y que permite que tenga lugar la violencia directa y la estructural.

3 El concepto de transformación pacífica de conflictos hace referencia a la tercera terminología que surge para hablar de los estudios de los conflictos. Con él se quiere poner el énfasis en la posibilidad de regular los conflictos por medios pacíficos y de entenderlos como situaciones inherentes a los seres humanos, con los cuales hay que aprender a convivir, evidentemente siempre que sean regulados de forma pacífica. En este sentido, provoca un giro en la interpretación de las situaciones conflictivas, aludiendo a la posibilidad de concebirlas en sentido negativo o positivo en función de los mecanismos utilizados para su regulación (Lederach, 1995).

4 En la Universitat Jaume I de Castellón (España) se viene trabajando en una filosofía para hacer las paces desde hace más de veinte años, de la mano de Vicent Martínez-Guzmán (2001 y 2005) y del grupo de investigadores de la Cátedra Unesco de Filosofía para la Paz. Se trata de una filosofía para hacer las paces, entendida como una "reconstrucción normativa de nuestras competencias para hacer las paces" (Martínez-Guzmán, 2005: 16), y que pone el énfasis en el análisis y la reflexión sobre todas aquellas cuestiones que inciden en la construcción y el mantenimiento de la paz. En este sentido, es una práctica multidisciplinar e interdisciplinar, y multicultural e intercultural, que aborda aspectos relativos a la educación 
las niñas y los niños en las escuelas (Martínez Guzmán, 2001 y 2005), sino también su hábito de pensamiento crítico, ético y creativo sobre estos temas. A consecuencia de ello, hay una rigidez en el modelo educativo tradicional que "niega a la educación y al conocimiento como procesos de búsqueda" (Freire, 1970: 77), lo cual lleva a las conclusiones de la siguiente cita:

Dictamos ideas. No cambiamos ideas. Dictamos clases. No debatimos o discutimos temas. Trabajamos sobre el educando. No trabajamos con él. Le imponemos un orden que él no comparte, al cual sólo se acomoda. No le ofrecemos medios para pensar auténticamente, porque al recibir las fórmulas dadas simplemente las guarda. No las incorpora, porque la incorporación es el resultado de la búsqueda de algo que exige, de quien lo intenta, un esfuerzo de recreación y de estudio (Freire, 2009: 67-68).

Se trata, pues, de una práctica educativa que beneficia la relación pedagógica asimétrica entre el profesorado y el estudiantado, y que les confiere la seguridad de seguir estando en su "zona de confort"; de seguir disfrutando de la comodidad de sus roles habituales. En este sentido, afirman Bourdieu y Passeron (2009: 97-98):

Tal vez estudiantes y profesores tengan en común la oscura intención de salvar las ventajas ocultas que les procura el sistema actual beneficiándose absolutamente de las ventajas manifiestas que les aseguraría el sistema opuesto, que es incompatible en tanto tal con el sistema actual. Del mismo modo que los profesores pueden lamentar la pasividad de los estudiantes sin ver que es el precio de la seguridad que deben a una relación pedagógica disimétrica, ciertos estudiantes pueden imputar únicamente al autoritarismo profesoral la pasividad en la que son mantenidos sin percibir que es la contrapartida de todas las protecciones y de todas las libertades que les asegura el anonimato de los anfiteatros.

\section{Educación liberadora y filosofía para hacer las paces. El diálogo con las niñas y los niños en las escuelas}

Las voces que se alzan en demanda de unas pedagogías alternativas a la bancaria reclaman sobre todo una mayor participación de las niñas y los niños en las escuelas, a través de una subversión de los roles del profesorado y del alumnado, según la cual el primero de estos agentes ya no ha de ser "sólo el que educa sino aquel que, en tanto educa es educado a través del diálogo con el educando, quien, al ser educado, también educa" (Freire, 1970: 90).

De hecho, ésta es la tesis que nutre la propuesta alternativa freiriana al modelo tradicional, la pedagogía liberadora o problematizadora, con la que

para la paz, al género, a la comunicación, a la transformación pacífica de los conflictos, etcétera. 
Freire quiere "poner en problema” al estudiantado, liberándolo de su pasividad en las aulas y haciéndolo participar activamente en el proceso de su aprendizaje, teniendo muy en cuenta las aportaciones que éste puede hacer a través de los diálogos establecidos con el profesorado.

En este sentido, las niñas y los niños "en vez de ser dóciles receptores de los depósitos se transforman ahora en investigadores críticos en diálogo con el educador, quien a su vez es también un investigador crítico" (Freire, 1970: 91). De este modo, la narrativa del profesorado pierde peso en favor de otras herramientas dialógicas, las cuales dan paso al mismo tiempo a una relación pedagógica mucho más simétrica entre el profesorado y el alumnado, así como a la necesidad de que ambos agentes escapen de sus "zonas de confort".

El profesorado, por un lado, siendo capaz de guiar actividades dinámicas que permitan escuchar la pluralidad de las voces de las niñas y los niños. El alumnado, por otro, atreviéndose a participar en dichas actividades, sin miedo a mostrar la diversidad de sus opiniones. Son éstas, por consiguiente, las prácticas que ponen el énfasis en diálogos que incitan a la reflexión, con las cuales el profesorado y las niñas y los niños "se transforman en sujetos del proceso en que crecen juntos" y en el cual "los argumentos de la autoridad" ya no rigen.

Proceso en el que ser funcionalmente autoridad requiere el estar siendo con las libertades y no contra ellas (Freire, 1970: 90). Se observa entonces que "la razón de ser de la educación liberadora radica en su impulso inicial conciliador" (Freire, 1970: 77). Un impulso que empieza con "la superación de la contradicción educador-educando" (Freire, 1970: 77) y que funde estos dos polos, "de tal manera que ambos se hagan, simultáneamente, educadores y educandos" (Freire, 1970: 77).

Esta razón de ser de la educación liberadora muestra, entre algunas otras ideas, que realmente se trata de una pedagogía que va de la mano de una transformación de aquella noción generalizada de la niñez, la cual hacía ver a las niñas y a los niños como personas que se encuentran en una etapa de la vida preparatoria para la edad adulta. Por el contrario, esta pedagogía alternativa se fundamenta en una concepción de la niñez entendida como un proceso de maduración (Murris, 1999: 24), donde las niñas y los niños dejan de ser fácilmente maleables para convertirse en agentes de sus propias acciones (Huynh et al., 2015: 43).

Desde esta interpretación, en efecto, las niñas y los niños pueden ser también educadores en las aulas (Haynes y Murris, 2013), quienes nutren los aprendizajes desde las visiones que tienen de las cosas, fruto de sus formas de vivir la vida (Huynh et al., 2015) y que, sin ninguna duda, pueden 
complementar las de las personas adultas, al hacérselas ver desde horizontes diferentes a los acostumbrados.

Con la pedagogía liberadora se trata de impulsar un discurso emancipador de las niñas y los niños (Cordero-Arce 2012 y 2015), que tiene muy en cuenta la multiplicidad de roles que pueden ejercer y que deconstruye una concepción única, con pretensiones universalizables de ellas y de ellos. Se trata de empoderarlos, reconociéndolos en su diversidad, desde sus cosmovisiones del mundo. Sólo así pueden tener primacía, y se pueden valorar positivamente las herramientas dialógicas frente a la narrativa del profesorado.

El papel del diálogo en la educación liberadora se ha puesto ya de manifiesto a medida que se está haciendo el recorrido por algunos de sus rasgos principales. Sin embargo, cabría incidir un poco más en las posibilidades que el diálogo ofrece para potenciar el pensamiento crítico, ético y creativo en las niñas y los niños. Al dialogar no sólo se abren las puertas a la reflexión sobre los contenidos del currículum más clásico, sino también sobre cualquiera de los temas que pueden afectar la vida de las personas, aunque éstos no sean identificados como contenidos marco de los saberes más especializados.

Y es que ciertamente la pedagogía problematizadora libera también a las niñas y a los niños al permitirles abordar de forma continuada otras cuestiones que, aun no siendo parte del currículo clásico, no dejan de ser igualmente importantes. En este sentido, la reflexión sobre la paz y/o los conflictos puede tener una presencia mucho más continua con la flexibilidad de la metodología dialógica del modelo liberador, a diferencia de lo que sucedía con la rigidez de la metodología narrativa del modelo bancario.

De ahí que sea posible relacionar directamente a la pedagogía liberadora con una filosofía para hacer las paces con niñas y niños, mediante la cual se potencie su pensamiento crítico, ético y creativo en torno a lo que atañe a la construcción y al mantenimiento de la paz. La tendencia debería ser la de extender la práctica de la filosofía para hacer las paces en las escuelas, como actividad para promover la reflexión en las niñas y los niños sobre temas como los derechos humanos, la noviolencia, la igualdad de género, la responsabilidad ciudadana, la regulación positiva de los conflictos, la interculturalidad, el sufrimiento medioambiental, la inmigración, la realidad de las personas refugiadas, etcétera.

Todo ello con la amplia pretensión de hacer de la educación "una educación mucho más global, crítica, emancipatoria, no sexista, solidaria, cooperativa, que evite la exclusión, transformadora..." (Dios-Diz, 2013: 158-159), y mucho más afín a los "cuatro objetivos interactivos que comparten todos los elementos de la Educación para la Cultura de la Paz" (Tuvilla-Rayo, 2004: 
404), que son: preparar para la noviolencia, responsabilidad de los ciudadanos del mundo, igualdad de actitudes e investigación crítica de alternativas (Tuvilla-Rayo, 2004: 404-405). El objetivo debería ser avanzar hacia una pedagogía liberadora que, más allá de basarse solamente en los datos empíricos, pudiese adoptar una actitud abierta frente a nuevas ideas y conocimientos (Noddings, 2016).

Con estas ideas a modo de referencia, la educación como "acción cultural en un medio específico” (Freire, 2015: 22), obtiene un carácter plenamente revolucionario, al ser concebida como "un proceso permanente de liberación” (Freire, 2015: 41) de las niñas y los niños, quienes, ante la posibilidad de poder escapar de la situación opresora característica de la pedagogía bancaria, ponen en práctica ahora su capacidad reflexiva y de pensamiento, teniendo a su disposición muchos más medios para valorar también, tal y como se ha señalado, cuestiones de sus propias realidades, con un carácter predominantemente crítico (Freire, 2009: 79).

La educación liberadora se convierte, entonces, en un "acto de valor" (Freire, 2009: 67), que "no puede temer el debate, el análisis de la realidad, ni puede huir de la discusión creadora, bajo pena de ser una farsa” (Freire, 2009: 67). Es decir, se transforma ante todo en "un intento constante de cambiar de actitud, de crear disposiciones democráticas" (Freire, 2009: 64), el cual facilita al alumnado "la discusión valiente de su problemática, de su inserción en esta problemática" (Freire, 2009: 60) y le advierte

de los peligros de su tiempo para que, consciente de ellos, gane la fuerza y el valor para luchar, en lugar de ser arrastrado a la predicción de su propio "yo", sometido a las prescripciones ajenas. Educación que lo coloque en diálogo constante con el otro, que lo predisponga a constantes revisiones, a análisis críticos de sus "descubrimientos", a una cierta rebeldía, en el sentido más humano de la expresión (Freire, 2009: 60).

La pedagogía liberadora consigue así una mayor motivación de las niñas y los niños en las escuelas y establece lazos con lo que Marina (2010a) llama la pedagogía del entusiasmo: aquella que exige al profesorado "tener mucho más presentes los fines de la educación, incluso en un gran mural en un lugar destacado del aula, para no olvidarnos, para ser capaces de poner en cuestión nuestras rutinas, nuestras prácticas, nuestros contenidos, nuestras metodologías, al menos, de cuando en vez..." (Dios-Diz, 2013: 158-159).

En este sentido, se trata de una pedagogía que nos hace "conocernos mejor, desarrollar profundas competencias, mirar nuestro entorno con otros ojos, despertar la curiosidad dormida" (Marina, 2011: 20) y que lleva al profesorado a crecer junto con el estudiantado. Marina (2010a: 73) lo resume del siguiente modo: 
Si yo explico a un alumno lo importante que me parece la filosofía, lo bonito que es pensar bien, lo necesario que es tener un pensamiento crítico para no dejarse llevar como borregos, lo que disfruto al leer a ciertos filósofos, puedo estar contagiándole mi entusiasmo, despertando su curiosidad y venciendo sus resistencias o un desconocimiento.

No cabe duda de que la práctica de la pedagogía liberadora entusiasma a medida que también contribuye a la formación de una ciudadanía comprometida y de una sociedad inteligente (Marina, 2010b), capaz de "resolver los problemas sociales, creando capital comunitario y ampliando las posibilidades de acción de sus miembros" (Marina, 2010b: 93), en contraposición con la sociedad estúpida (Marina, 2010b), que "crea más problemas de los que resuelve, destruye capital comunitario y entontece o encanalla a sus ciudadanos" (Marina, 2010b: 93).

Una de las pocas experiencias de este tipo de pedagogía liberadora tiene lugar en la escuela de la Filosofía con Niñas y Niños, la cual nace con Lipman en los años setenta, con el objetivo de fomentar la actividad filosófica desde edades tempranas (Lipman, 1988 y 1993; Lipman y Sharp, 1978; Vansieleghem y Kennedy, 2011). Inspirándose en la filosofía socrática (Smith, 2011) e influido por Leonard Nelson (Arnaiz, 2007: 36), quien consideraba que era imprescindible "enseñar a filosofar a través de una didáctica no dogmática, que privilegiase el descubrimiento personal de los alumnos”, Lipman idea la comunidad de indagación filosófica en la cual las niñas y los niños, sentados en círculo, son los principales encargados de su aprendizaje, estructurado mediante diálogos (Jasinski y Lewis, 2016) a partir de preguntas que son resultado de la lectura de cuentos en el aula (Haynes, 2004).

De este modo, lo que busca la Filosofía con Niñas y Niños es desarrollar "skills for thinking critically, reflectively and reasonably" (Biesta, 2011:306), así como priorizar el "critical, emotional, political and ethical know-how" (Gregory, 2011: 202). Por este mismo motivo, entiende que la tarea del profesorado no es otra más que la de "helping the children to build on each other's ideas, resulting in a way of talking we are unfamiliar with, not only in education, but in our society generally" (Murris, 2000a: 40).

Uno de los principales aspectos que se ha cuestionado a la escuela de la Filosofía con Niñas y Niños desde sus inicios, ha tenido que ver justamente con la capacidad de las y los más pequeños para filosofar. Sin embargo, Murris (2000b) advierte que estas dudas sólo son posibles si se piensa que la filosofía no es nada más que un "cuerpo de contenidos", sin poder llegar a ser concebida también como una actividad que impulsa la práctica del filosofar. 
Se entiende que esta última interpretación, la de la filosofía como actividad, es la que realmente se promueve desde la Filosofía con Niñas y Niños, pues es una escuela que, más que poner el énfasis en los conocimientos adquiridos sobre teorías filosóficas concretas, presta atención a la capacidad de las y los más pequeños para pensar crítica, ética y creativamente. Pensamientos naturales también a las niñas y a los niños, quienes no hay duda de que pueden reflexionar por sí mismos, hablar de sus propias ideas y ponerlas en relación con otras en un diálogo organizado (Murris, 2000b: 262).

De hecho, para Smith (2011:222), por ejemplo, la actividad del filosofar es llevada a cabo por las niñas y los niños como si de un juego se tratara, cuando afirma que "the playing of games comes very easily to children" (Smith, 2011: 222), de tal modo que "they can easily very encouraged to compare the ways that rules function in a game and the way that they apply to moral conduct" (Smith, 2011: 222), haciendo que su práctica filosófica adopte multitud de formas.

Bajo dicha noción de la filosofía, esta escuela ha ido ampliando sus temáticas de análisis desde sus orígenes con Lipman (Murris, 2016), tal y como se puede observar en algunos trabajos de Sátiro (2011a y 2013), quien, habiendo centrando sus investigaciones sobre todo en el estudio del pensamiento creativo, ha emprendido algunas publicaciones sobre los beneficios de la metodología de la escuela de Filosofía con Niñas y Niños para la reflexión sobre el desarrollo, la inclusión social y el bien común, entre otros temas.

Estas cuestiones encajan a la perfección con los ámbitos de aplicación de la filosofía para hacer las paces. La propuesta sería entonces, como se señalaba anteriormente, avanzar hacia una mayor práctica en las escuelas de la Filosofía con Niñas y Niños, la cual, afín a la pedagogía liberadora previamente descrita, podría seguir complementando sus materiales más clásicos con otros con los que fuese mucho más factible la reflexión sobre cuestiones relativas a la construcción de la paz y a la transformación pacífica de los conflictos.

En este sentido, los Cuentos por teléfono, de Rodari (2012), podrían ser incorporados para mostrar, también respecto a la paz, los sentires ocultos detrás de las opiniones de las niñas y los niños, las debilidades y fortalezas de sus argumentos y las consecuencias de sus opiniones (Hoyos-Valdés, 2010: 160). Todo ello sin obviar las reglas del juego del quehacer filosófico, las cuales para Hoyos-Valdés (2010: 154) son: tratar de ser relevante, consistente, coherente y no autocontradictorio.

En definitiva, se trataría de pensar crítica, ética y creativamente sobre aquello que envuelve a la paz y a la transformación de los conflictos por medios pacíficos, ejercitando "la mente por medio del pensamiento discipli- 
nario y estimulante y de una interacción estructurada" (Haynes, 2004: 33), gracias a la cual las niñas y los niños aprendiesen a objetar el razonamiento débil, a construir argumentos sólidos, a aceptar la responsabilidad de sus contribuciones, a admitir su dependencia respecto a las otras y los otros, a practicar de forma colaborativa en la autocorrección, a seguir la investigación hasta donde ésta les llevase y a sentirse personas orgullosas de los avances del grupo como un todo y de los suyos propios (De la Garza, 1998: 137).

Así, tendría lugar una filosofía para hacer las paces con las niñas y los niños como pedagogía liberadora en las escuelas, en la que las y los más pequeños, conservando muchos de los rasgos de la comunidad de indagación filosófica, serían capaces de dar sentido al mundo y de afrontar los desafíos de una sociedad cada vez más complicada (García-Moriyón, 2006).

\section{Educación liberadora. Hacia el pensamiento creativo en la filosofía para hacer las paces con niñas y niños}

En las secciones anteriores, se ha visto que el papel del diálogo en la escuela de Filosofía con Niñas y Niños como pedagogía liberadora es esencial. Su primacía supone, al estilo de las defensas llevadas a cabo por el filósofo clásico Isócrates (Fernández-Santillán, 2016), una llamada al papel de la palabra como medio transformador. Y es que, ciertamente, el diálogo es una "exigencia existencial" (Freire, 1970: 105), que:

Nace de una matriz crítica y genera crítica (Jaspers). Se nutre del amor, de la humildad, de la esperanza, de la fe, de la confianza. Por eso sólo el diálogo comunica. Y cuando los polos del diálogo se ligan así, con amor, esperanza y fe uno con el otro, se hacen críticos en la búsqueda de algo. Se crea, entonces, una relación de simpatía entre ambos. Sólo ahí hay comunicación (Freire, 2009: 80).

La herramienta dialógica fomenta, tal y como se puede observar en la cita anterior, una "pedagogía de la comunicación" (Freire, 2009: 81), mediante la cual las niñas y los niños pueden llegar a reconocer que hay "prácticas discursivas diversas, usos de metáforas distintas, maneras de hacernos las cosas unos seres humanos diferentes a las que se conciben a sí mismas como reales" (Martínez-Guzmán, 2001: 146).

Es decir, a través del diálogo con las otras y los otros, las niñas y los niños pueden poner en cuestión sus formas habituales de ver y hacer las cosas, ampliando sus puntos de vista y valorando otras perspectivas posibles, gracias a una revalorización de todas las voces. Actitudes que permiten empezar a practicar en las escuelas una filosofía para hacer las paces con las niñas y los niños, que estimula su pensamiento crítico, ético y creativo en torno a la paz y a la transformación pacífica de los conflictos. 
En el texto se ha concebido también el diálogo como un medio potenciador del pensamiento crítico, ético y creativo en la pedagogía liberadora y en la Filosofía con Niñas y Niños. Para ello, se ha seguido principalmente a Lipman (1988 y 1993), quien cree que éstas son las tres partes en las cuales se desglosa la capacidad de pensamiento.

En este sentido, cuando habla del pensamiento crítico se refiere al pensamiento que se puede utilizar para dar sentido a los textos que leemos, a las imágenes que vemos o a las palabras que escuchamos, con el fin de opinar al respecto y de decidir si se está de acuerdo o no con lo que hemos leído, visto, escuchado... (Pritchard, 1998: 74-75).

Con la noción de pensamiento ético alude a la posibilidad de ponernos en la posición de otras personas, comprendiendo de manera empática los distintos puntos de vista sobre una misma cuestión (Greene, 2005). Y finalmente con la idea de pensamiento creativo designa la capacidad humana para generar más, nuevas y mejores ideas (Csikszentmihaly, 1998; Sátiro, 2011b: 136), a través de la captación de fuentes de la experiencia (Sátiro, 2002: 147). Capacidad que se vincula directamente con las competencias para imaginar y razonar de manera analógica (Sátiro, 2005: 47) y que tiene como algunos de sus rasgos básicos a la flexibilidad, la originalidad, la fluidez y la elaboración (Sátiro, 2005: 47).

En este momento, y sin con ello querer disminuir la relevancia del pensamiento crítico y ético, cabría centrar un poco más la atención en el pensamiento creativo. Cabría hacerlo así porque si hasta el momento se ha puesto el énfasis en la necesidad de una filosofía para hacer las paces con las y los más pequeños que, de acuerdo con los rasgos de la pedagogía liberadora y de la escuela de Filosofía con Niñas y Niños, ha de posibilitarles la reflexión sobre aquello que envuelve a la paz y a la transformación pacífica de los conflictos, en este lugar se debería subrayar la idea según la cual se cree que la creatividad tiene un rol fundamental para la construcción de la paz y la regulación positiva de las situaciones conflictivas; por lo tanto, se entiende que debe ocupar una posición destacada en una propuesta de filosofía para hacer las paces con las niñas y los niños en las escuelas, propuesta que ayudará a poner en práctica a un mismo tiempo, tal y como se está viendo, los rasgos de la pedagogía liberadora y de la escuela de Filosofía con Niñas y Niños.

De esta manera y para trabajar la creatividad desde la pedagogía liberadora, no cabe duda de que se dispone de gran variedad de actividades que se pueden practicar en la filosofía para hacer las paces con las y los más pequeños (Barbeito-Thonon y Caireta, 2010), con las que además es posible seguir abordando temas relativos a la paz y los conflictos de acuerdo con los modos de proceder de la comunidad de indagación filosófica. 
Asimismo, también es importante rescatar aquí que las referencias a la creatividad han sido puestas encima de la mesa previamente por investigadores del ámbito de la peace research, quienes no han dudado en señalar el papel que la imaginación, entendida como competencia humana posibilitadora del pensamiento creativo, juega en pro de la paz y de la transformación de los conflictos por medios pacíficos. Investigadores que, por consiguiente, deberán tenerse en cuenta en una propuesta de filosofía para hacer las paces con niñas y niños como pedagogía liberadora.

Por mencionar algunos de estos autores, se puede citar a Martínez Guzmán (2005), quien subraya en su último libro la necesidad de potenciar la competencia imaginativa o a Ross (1995), quien resalta la importancia de buscar soluciones creativas a los conflictos. Y a Lederach (2007), al defender la presencia de la imaginación moral en la transformación pacífica de las situaciones conflictivas, definiéndola como

la capacidad de imaginar algo anclado en los retos del mundo real pero a la vez capaz de dar a luz aquello que aún no existe. En referencia a la construcción de la paz, ésa es la capacidad de imaginar y generar respuestas e iniciativas constructivas que, estando enraizadas en los retos cotidianos de la violencia, trasciendan y en última instancia rompan los amarres de esos patrones y ciclos destructivos (Lederach, 2007: 63-64).

Iniciativas constructivas que tienen lugar cuando salta esa chispa que lleva, de manera inesperada, a una solución para el conflicto. Para Lederach (2007), esa chispa es fruto de la serendipia de la imaginación, la cual se compone de los tres siguientes rasgos: de la capacidad para percibir más allá de lo que hay, incluso, a la vista, de la capacidad de crear percepciones nuevas que cambian la interpretación de las cosas, y de la cualidad de trascendencia que permite trascender realidades y desarrollar actos creativos (Lederach, 2007: 61).

Esos tres rasgos llevan a apreciar, al mismo tiempo, los que serían los cuatro componentes básicos de la imaginación moral para este autor: la centralidad de las relaciones, la curiosidad paradójica, el acto creativo y la voluntad de arriesgar.

En esta misma línea, García-González (2014) resalta el papel de la imaginación ética como recurso "auxiliar de la razón", el cual la hace "más abierta e incluyente” (García-González, 2014: 21) al contener la capacidad para pensar en el futuro, evitando así muchas de las dudas que a veces se le pueden presentar a la razón. De este modo, define la imaginación ética como "un recurso rico, pleno y humano" (García-González, 2014: 21), que se enraiza en la propia realidad, sin fugarse del mundo; es "condición de posibilidad de la creatividad misma” (García-González, 2014: 22). 
Esta interpretación es por la cual García-González (2014) afirma que la percepción del mundo lleva a la imaginación ética a la deconstrucción del pasado para una posterior reconstrucción del futuro, con la cual se abren nuevos espacios y se lleva al "campo de lo posible más allá de lo actual" (GarcíaGonzález, 2014: 23) en todas las esferas de la vida y, por lo tanto, también en escenarios marcados por la existencia de conflictos violentos.

Ello sólo puede tener lugar si se piensa en la imaginación ética como la competencia humana que hace posible replantear algunos "supuestos y reposicionarlos, intentando sortearlos y emplazar a la paz -como objetivo a lograr-como un nuevo escenario susceptible de convertirse en realidad" (García-González, 2014: 8). Dice García-González (2014: 4) que "estamos obligados a ser buscadores de paz y encontrar rumbos hacia los cuales ir, repensando la realidad frente a nosotros para indagar alternativas posibles desde una imaginación de carácter ético". En efecto:

La superación de la violencia, su trascendencia y la transformación de la sociedad requieren de procesos de cambio, de toma de conciencia y de apertura razonable y ética para poder pensar creativamente en situaciones mejores y más justas para todos los miembros de la sociedad. Ciertamente esta superación también se relaciona con una forma creativa e imaginativa de lidiar con los conflictos para finalmente incluir la realización de procesos de reconciliación (García-González, 2014: 5-6).

Por consiguiente, García-González (2014: 24) entiende que "la búsqueda de lo imaginable o lo inimaginable, de lo inesperado y de aquello que emerge de la creatividad, es lo que podrá dar luces para concebir y favorecer proyectos de paz", siempre mediante diálogos que han de ser apuntalados "por el carácter imaginativo y creativo para superar la situaciones conflictuales" (García-González, 2014: 17).

En resumen, lo que se quiere es revalorizar el pensamiento creativo y, fruto de ello, también a la imaginación como competencia posibilitadora de la creatividad para inventar nuevas formas de hacernos las cosas, y para mantener una "actitud activa, expresiva y capaz de movilizar los recursos de que se dispone” (Marina y Marina, 2013: 67), en torno a la construcción de la paz y a la transformación pacífica de los conflictos.

Esto mediante una filosofía para hacer las paces con niñas y niños en las escuelas que, como práctica de la pedagogía liberadora y conservando muchos de los rasgos de la comunidad de indagación filosófica propia de la escuela de Filosofía con Niñas y Niños, subvierta, por un lado, la noción del alumnado, entendiendo ahora a las niñas y los niños como sujetos comprometidos con su propio aprendizaje y como una futura ciudadanía crítica, ética, creativa, capaz de imaginar otros mundos posibles. Y, por otro, transforme los centros 
educativos en espacios creativos, estimulantes y favorables a la discusión de ideas con las niñas y los niños.

\section{Conclusiones}

Se detallan, a continuación, las principales conclusiones alcanzadas en estas páginas:

1. La pedagogía bancaria, basada en la estrategia narrativa del profesorado, en los saberes especializados y en una visión infantilizada de las niñas y los niños sigue disfrutando de una posición privilegiada en las escuelas.

2. La pedagogía liberadora, defensora de la práctica de metodologías dialógicas en las escuelas y de una noción de las niñas y los niños que les empodere como agentes de sus acciones, ocupa espacios muy reducidos en el contexto de la educación formal.

3. La escuela de filosofía con niñas y niños, ideada en los años setenta por Lipman, se puede concebir como una experiencia de pedagogía liberadora, gracias a su propuesta de la comunidad de indagación filosófica.

4. La filosofía para hacer las paces con niñas y niños en las escuelas es posible en el marco de la pedagogía liberadora, al tratarse de un modelo educativo que permite, entre otras cosas, el diálogo y la reflexión sobre contenidos ajenos a los propios del currículum clásico.

5. El objetivo de la filosofía para hacer las paces con niñas y niños como pedagogía liberadora es impulsar en las escuelas, mediante diálogos, su pensamiento crítico, ético y creativo, sobre lo que atañe a la construcción de la paz y a la transformación pacífica de los conflictos. En este sentido, conserva muchos de los rasgos de una comunidad de indagación filosófica.

6. El pensamiento creativo debe ocupar una posición destacada en la actividad de la filosofía para hacer las paces con niñas y niños en las escuelas, debido a su papel ineludible para la construcción de la paz y la transformación pacífica de los conflictos.

7. El trabajo en la creatividad favorece la formación de niñas y niños mucho más comprometidos con su aprendizaje, así como su predisposición para llegar a ser una futura ciudadanía crítica, capaz de idear otros mundos posibles. 
Convergencia Revista de Ciencias Sociales, núm. 75, 2017, Universidad Autónoma del Estado de México

\section{Referencias}

Arnaiz, Gabriel (2007), "Evolución de los talleres filosóficos: de la filosofía para niños a las nuevas práctica filosóficas”, en Childhood \& Philosophy, vol. 3, núm. 5, Brasil: Universidad Estatal de Río de Janeiro.

Barbeito-Thonon, Cécile y Caireta, Marina (2010), Juegos de paz. Caja de herramientas para educar hacia una cultura de paz, España: Los Libros de la Catarata.

Biesta, Gert (2011), "Philosophy, Exposure, and Children: How to resist the instrumentalisation of Philosophy in Education", en Journal of Philosophy of Education, vol. 45, núm. 2, Oxford \& Malden: The Philosophy of Education Society of Great Britain.

Bourdieu, Pierre y Passeron, Jean-Claude (1967), Los estudiantes y la cultura, España: Labor.

Bourdieu, Pierre y Passeron, Jean-Claude (2001), La reproducción. Elementos para una teoría del sistema de enseñanza, España: Popular.

Bourdieu, Pierre y Passeron, Jean-Claude (2009), Los herederos. Los estudiantes y la cultura, Argentina: Siglo XXI.

Cordero-Arce, Matías (2012), “Towards an emancipatory discourse of children's rights”, en The International Journal of Children's Rights, vol. 20, núm, 3, Inglaterra: Brill.

Cordero-Arce, Matías (2015), Hacia un discurso emancipador de los derechos de las niñas y los niños, Perú: IFEJANT.

Csikszentmihalyi, Mikaly (1998), Creatividad. El fluir y la psicología del descubrimiento y la invención, España: Paidós.

De la Garza, María (1998), "La comunidad de investigación como medio de educación moral”, en García-Moriyón, Félix [ed.], Crecimiento moral y filosofía para niños, España: Desclée de Brouwer.

Dios-Diz, Manuel (2013), "El currículum de la noviolencia en la educación para la paz”, en Comins-Mingol, Irene y Muñoz, Francisco [eds.], Filosofias y praxis de la paz, España: Icaria.

Fernández-Santillán, José (2016), "Isócrates y los orígenes de la educación cívica. Actualidad de un pensador clásico”, en Convergencia. Revista de Ciencias Sociales, núm. 71, México: Universidad Autónoma del Estado de México.

Freire, Paulo (1970), Pedagogía del oprimido, España: Siglo XXI.

Freire, Paulo (2009), La educación como práctica de la libertad, España: Siglo XXI.

Freire, Paulo (2015), Pedagogía liberadora, España: Los Libros de la Catarata.

Galtung, Johan (2003), Paz por medios pacificos. Paz, conflicto, desarrollo y civilización, España: Gernika Gogoratuz.

García-González, Elvira (2014), "Hacia una prospectiva de paz a partir del realismo de la violencia: una construcción desde la imaginación ética”, en García-González, Elvira [coord.], Trascender la violencia. Criticas y propuestas interdisciplinarias para construir la paz, México: Porrúa.

García Moriyón, Félix (2006), Pregunto, dialogo, aprendo: cómo hacer filosofía en el aula, España: Ediciones de La Torre.

Greene, Maxine (2005), Liberar la imaginación: ensayos sobre educación, arte y cambio social, España: Graó.

Gregory, Maughn (2011), "Philosophy for children and is critics: A Mendham Dialogue", en Journal of Philosophy of Education, vol. 45, núm. 2, Gran Bretaña: The Philosophy of Education Society of Great Britain. 
Haynes, Joanna (2004), Los niños como filósofos. El aprendizaje mediante la indagación y el diálogo en la escuela de primaria, España: Paidós Ibérica.

Haynes, Joanna y Murris, Karin (2013), "Child as educator: introduction to the special issue”, en Studies in Philosophy and Education, vol. 32, núm. 3, Países Bajos: Springer Netherlands.

Hoyos-Valdés, Diana (2010), "Filosofía para niños y lo que significa una educación filosófica", en Discusiones filosóficas, año 11, núm 16, Colombia: Departamento de Filosofía de la Universidad de Caldas.

Huynh, Kim et al. (2015), Children and global conflict, Inglaterra: Cambridge University Press.

Jasinski, Igor y Lewis, Tyson (2016), “Community of Infancy: Suspending the Sovereignty of the Teacher's Voice”, en Journal of Philosophy of Education, vol. 50, núm. 4, Gran Bretaña: The Philosophy of Education Society of Great Britain.

Kohan, Walter (2011), "Childhood, Education and Philosophy: Notes on Deterritorialisation”, en Journal of Philosophy of Education, vol. 45, núm. 2, Gran Bretaña: The Philosophy of Education Society of Great Britain.

Lederach, John (1995), Preparing for Peace. Conflict Transformation Across Cultures, Estados Unidos: Syracuse University Press.

Lederach, John (2007), La imaginación moral. El arte y el alma de la construcción de la paz, España: Bakeaz.

Lipman, Mathew (1988), Philosophy goes to school, Philadelphia: Temple U. Press.

Lipman, Mathew (1993), Thinking children and education, Estados Unidos: Kendall-Hull.

Lipman, Mathew y Sharp, Margaret (1978), Growing up with Philosophy, Estados Unidos: Temple University Press.

Marina, José (2010a), La educación del talento, España: Planeta.

Marina, José (2010b), Las culturas fracasadas. El talento y la estupidez de las sociedades, España: Anagrama.

Marina, José (2011), Los secretos de la motivación, España: Planeta.

Marina, José y Marina, Eva (2013), El aprendizaje de la creatividad, España: Planeta.

Martínez-Guzmán, Vicent (2001), Filosofía para hacer las paces, España: Icaria.

Martínez-Guzmán, Vicent (2005), Podemos hacer las paces: reflexiones éticas tras el 11-S y el 11-M, España: Desclée de Brouwer.

Murris, Karin (1999), "Philosophy with preliterate children”, en Thinking: The Journal of Philosophy for Children, vol. 14, núm. 4, Estados Unidos: Institute for the Advancement of Philosophy for Children.

Murris, Karin (2000a), “The role of the Facilitator in Philosophy Enquiry”, en Thinking: The Journal of Philosophy for Children, vol. 15, núm. 2, Estados Unidos: Institute for the Advancement of Philosophy for Children.

Murris, Karin (2000b), “Can children do Philosophy?”, en Journal of Philosophy of Education, vol. 34, núm. 2, Gran Bretaña: The Philosophy of Education Society of Great Britain.

Murris, Karin (2016), “The philosophy for children curriculum: resisting 'Teacher Proof' Texts and the Formation of the Ideal Philosopher Child", en Studies in Philosophy and Education, vol. 35, núm. 1, Países Bajos: Springer Netherlands.

Naciones Unidas (1989), Convención sobre los derechos del niño, Madrid: Unicef Comité Español. Disponible en: http://www.un.org/es/events/childrenday/pdf/derechos.pdf [28 de marzo de 2017]. 
Noddings, Nel (2016), Educació per la pau. Com arribem a estimar i a odiar la guerra, España: Pagès Editors.

Pavez Soto, Iskra (2012), "Sociología de la infancia: las niñas y los niños como actores sociales”, en Revista de Sociología, núm. 27, Chile: Universidad de Chile.

Perrenoud, Philippe (1990), La construcción del éxito y del fracaso escolar, España: Ediciones Morata.

Perrenoud, Philippe (2006), El oficio de alumno y el sentido de trabajo escolar, España: Popular.

Perrenoud, Philippe (2007), Pedagogía diferenciada. De las intenciones a la acción, España: Popular.

Pritchard, Michael (1998), “Desarrollo moral y filosofía para niños”, en García-Moriyón, Félix [ed.], Crecimiento moral y filosofía para niños, España: Desclée de Brouwer.

Rodari, Gianni (2012), Cuentos por teléfono, España: Juventud.

Ross, Marc (1995), La cultura del conflicto: las diferencias interculturales en la práctica de la violencia, España: Paidós.

Sátiro, Angélica (2002), “CCrear? Un artículo para dialogar”, en Lipman, Mathew [ed.], Filosofía y Educación, España: Ediciones de la Torre.

Sátiro, Angélica (2005), "Cómo el pensamiento vuela cuando jugamos a pensar creativamente...”, en VVAA [coords.], Filosofía en la escuela. La práctica de pensar en las aulas, España: Graó.

Sátiro, Angélica (2011a), "La creativitat com a motor de desenvolupament i d'inclusió social”, en Cantabou, núm. 33, España: Centre de Professorat d'Inca.

Sátiro, Angélica (2011b), "Pedagogia per a una ciutadania creativa”, en Temps d'Educació, núm. 40, España: Universitat de Barcelona.

Sátiro, Angélica (2013), “La capacidad creativa como generadora del bien común”, en Crearmundos, núm. 11, España: Associació Cultural per la Creativitat i la Innovació.

Smith, Richard (2011), "The play of Socratic Dialogue”, en Journal of Philosophy of Education, vol. 45, núm. 2, Gran Bretaña: The Philosophy of Education Society of Great Britain.

Storme, Thomas y Vliegue, Joris (2011), “The experience of Childhood and the Learning Society: Allowing the child to be philosophical and Philosophy to be Childish", en Journal of Philosophy of Education, vol. 45, núm. 2, Gran Bretaña: The Philosophy of Education Society of Great Britain.

Tuvilla-Rayo, José (2004), “Cultura de Paz y Educación”, en Molina-Rueda, Beatriz y Muñoz, Francisco [ed.], Manual de Paz y conflictos, España: Universidad de Granada.

Vansieleghem, Nancy y Kennedy, David (2011), "What is Philosophy for Children, What is Philosophy with Children-After Mathew Lipman?”, en Journal of Philosophy of Education, vol. 45, núm. 22, Gran Bretaña: The Philosophy of Education Society of Great Britain.

Sonia París-Albert. Doctora por la Universitat Jaume I (Castellón, España) y Profesora Contratada Doctora en el área de Filosofía del Departamento de Filosofía y Sociología de la misma universidad. Actualmente es Vicedirectora de la Cátedra Unesco de Filosofía para la Paz y Coordinadora del Máster Universitario en Estudios Internacionales de Paz, Conflictos y Desarrollo de 
la Universitat Jaume I (Castellón, España). Principales líneas de investigación: historia de la filosofía, la filosofía para la paz, la transformación pacífica de los conflictos, filosofía con niñas y niños y pensamiento creativo. Publicaciones recientes: París Albert, Sonia, "Repensar los conflictos interculturales y su transformación pacífica desde el paradigma de la complejidad de Heráclito de Efeso", en THÉMATA. Revista de Filosofía, núm. 52, (2015); París Albert, Sonia, "Hacia una revalorización de la filosofía en diálogo con la indignación”, Convergencia. Revista de Ciencias Sociales, núm. 68, mayoagosto, México: Universidad Autónoma del Estado de México (2015); París Albert, Sonia, "Indignación para la acción: un reencuentro con la filosofía de Friedrich Nietzsche”, en Benet, Vicente José y Arévalo Salinas, Álex [eds.], De victimas a indignados. Imaginarios del sufrimiento y de la acción politica, Valencia: Tirant Humanidades (2016).

Recepción: 13 de abril de 2017.

Aprobación: 19 de junio de 2017. 
